\title{
PREVALENCE OF HIV INFECTION IN THE ICTC CENTRE OF SILCHAR MEDICAL COLLEGE, ASSAM
}

\author{
Debadatta Dhar Chanda1, Atanu Chakravarty2, Kabita Choudhury33, Chirasree Deb ${ }^{4}$, Arnabjyoti Bhagawati 5
}

${ }_{1}^{1}$ Associate Professor, Department of Microbiology, Silchar Medical College and Hospital, Silchar, Assam. ${ }^{2}$ Assistant Professor, Department of Microbiology, Silchar Medical College and Hospital, Silchar, Assam. 3Postgraduate Trainee, Department of Microbiology, Silchar Medical College and Hospital, Silchar, Assam. 4Postgraduate Trainee, Department of Microbiology, Silchar Medical College and Hospital, Silchar, Assam. ${ }_{5}^{5}$ Technical Officer, Department of Microbiology, Silchar Medical College and Hospital, Silchar, Assam.

\section{BACKGROUND} ABSTRACT

Silchar, in south eastern region of Assam is the gateway of many north eastern states like Manipur, Mizoram and Tripura. Therefore, ICTC, Silchar Medical College and Hospital, Silchar is attended by patients from Assam and neighbouring states. This study was taken considering the geographical location and high prevalence of HIV here.

Objective- To study the prevalence of sero-positivity rate of HIV infection among clients reporting to ICTC SMCH, Silchar from January 2012 to December 2014.

\section{MATERIALS AND METHODS}

The clients were attendees of both OPD and indoor patients of SMCH or came voluntarily to know their HIV status. After counselling and consent, antibody testing was done using rapid kits and reactivity declared as per NACO guidelines. The data was assessed by age, sex, occupation, educational level, marital status, behavioural patterns and source of exposure. Data was collected, compiled and analysed using standard statistical methods.

Study Design- Retrospective cross-sectional study.

\section{RESULTS}

Of the 18,763 clients tested in the span of this 3 years, $774(4.12 \%)$ were positive for HIV. The sero-positivity rate varied from $3.61 \%$ in 2012, 4.61\% in 2013 and 4.36\% in 2014. Prevalence in male clients amounted to $2.8 \%$ and in female clients was $1.3 \%$. Majority of the sero-positive clients fell in the age group of $30-45$ years (51.8\%). The predominant occupation were drivers $(19.76 \%)$ and housewives (23\%). 88.5\% of them exhibited heterosexual behaviour, parent to child transmission was $5.42 \%$ and $3.48 \%$ were IDU. Most of the clients had only primary level education $(70 \%)$ or were illiterate $(18.63 \%)$.

\section{CONCLUSION}

ICTCs are important for prevention, detection and care of HIV infection. The findings from their clients indicate a high seropositivity among both genders. Multiple heterosexual contact, especially in migrants are main route of transmission of HIV causing spread also to spouses. Awareness program following similar studies hence may reduce further spread of HIV.

\section{KEYWORDS}

Prevalence, ICTC, South Eastern Assam.

HOW TO CITE THIS ARTICLE: Chanda DD, Chakravarty A, Choudhury K, et al. Prevalence of HIV infection in the ICTC centre of Silchar Medical College, Assam. J. Evolution Med. Dent. Sci. 2018;7(12):1516-1519, DOI: 10.14260/jemds/2018/343

\section{BACKGROUND}

Recognised as an emerging disease in the early 1980s, HIV/AIDS has infected tens of millions of people in the last 20 years.(1) There are approximately 3.4 crores people living with HIV and about 3 crores people have died of AIDS related causes since the beginning of the epidemic.(2)-(4) Latest worldwide survey data show a $50 \%$ reduction in the rate of new HIV infections (HIV incidence) achieved in 25 (low and middle income countries). India with a burden of 2.5 million people with HIV-1 infection makes it only the third largest HIV-1 epidemic in the world after Africa and Nigeria.(5)

'Financial or Other Competing Interest': None.

Submission 05-02-2018, Peer Review 04-03-2018,

Acceptance 10-03-2018, Published 19-03-2018.

Corresponding Author:

Dr. Debadatta Dhar Chanda,

Associate Professor, Department of Microbiology,

Silchar Medical College and Hospital, Silchar, Assam.

E-mail: drdebadattadhar@rediffmail.com

DOI: $10.14260 /$ jemds $/ 2018 / 343$

(c) $(1)$
The HIV virus/ AIDS epidemic has devastated many individuals, families and communities. As the epidemic evolves further, rates will continue to rise in communities and nations where poverty, social inequalities and weak health infrastructure facilitate spread of the virus.(6) It is difficult to estimate the actual HIV burden in India, as the estimate for India is based primarily on anonymous testing data from public clinics of antenatal care, patients in high risk groups or with sexually transmitted infections. Although, the number of surveillance sites is expanding, the data may still be skewed and inadequate as one percent increase in the HIV prevalence in adults would result in additional five million infected people, i.e. small changes in prevalence could translate to large absolute numbers of infected individuals and that is why true prevalence is still disputed.(7)-(8)

Under NACP-III, Voluntary Counselling and Testing Centres (VCTCs) and facilities providing Prevention of Parent to Child Transmission of HIV/ AIDS (PPTCT) are remodelled as a hub or Integrated Counselling and Testing Centre (ICTC) to provide services to all clients under one roof. An ICTC is a place where a person is counselled and tested for HIV on his 
own free will or on advice of a medical practitioner. The ICTC data is important to throw light on the epidemiological profile of HIV positive individuals. This will help not only to identify the various risk groups, but also give direction for priority targeted intervention to reduce HIV transmission in the community.

With this background, present study was undertaken with the objectives to study the prevalence of sero-positivity rate of HIV infection among clients reporting to ICTC SMCH, Silchar from January 2012 to December 2014.

\section{Study Design}

Retrospective cross-sectional study.

\section{MATERIALS AND METHODS}

This Cross-Sectional study was conducted for a time period of three years (3 years) between January 2012 to December 2014 among all attendees of ICTC, Silchar Medical College and Hospital, coming either voluntarily or being referred from various departments of the hospital. All the essential information were collected from the attendees by interviewing them. The variables studied included age, sex, marital status, occupation, place of residence, pattern of risk behaviour and HIV serostatus noted.

Following the guidelines of NACO, the counsellor of the ICTC interviewed the attendees under strict confidentiality. After pre-test counselling and obtaining consent of the attendees, laboratory technician of ICTC collected their blood samples. All clients at ICTC were given unique PID number. The HIV test was done in the HIV testing laboratory, which is NABL accreditated since 2014 as per NACO guidelines with 3 rapid test kits provided by ASACS/ NACO.

The protocol of the NACO tests performed as per NACO guidelines was as follows:

The first test kit Comb AIDS was of highest sensitivity and specificity increases with second and third kit. Therefore, when the first test kit is negative, second meriscreen and third AIDS scan kits were not done and the result is negative for the tested sample. If the first test is positive, then second and third rapid test kits were performed and if these two tests were also positive then the final result was given as positive for the tested sample.

\section{RESULTS}

In this study, the prevalence of HIV was found to be $4.12 \%$. Of the 18,763 clients tested in the span of this 3 years, 774 (4.12\%) were positive for HIV-1. Highest sero-positivity was seen in 2013 (4.61\%), but more number of clients were tested in 2012 (7727).

Maximum number of sero-positivity was seen in male clients $(68.47 \%)$ followed by female clients $(31.52 \%)$ with no transgenders. Data is shown in Figure 1.

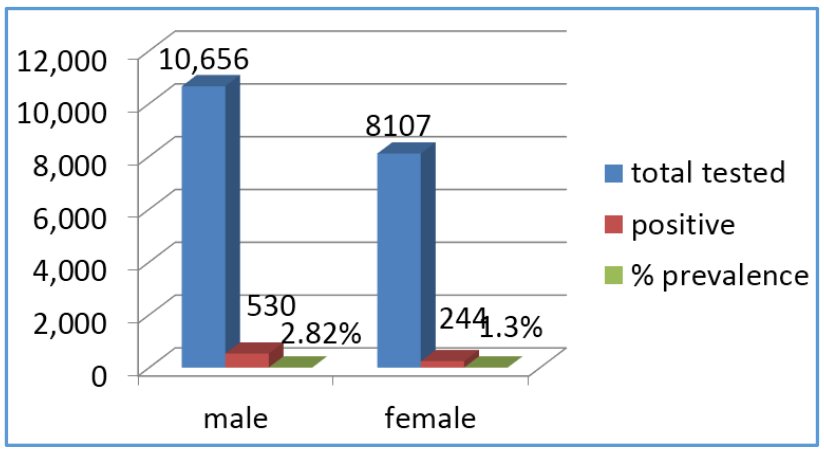

Maximum number of clients tested sero-positive in the age group of $30-45$ years (51.8\%) followed by $35.91 \%$, $12.14 \%$ and $5.16 \%$ in $15-30$ years, $\geq 45$ years, $\leq 15$ years of age respectively. 436 of the sero-positive clients were married males posing a threat to their spouses. Table 1 shows the marital status of the sero-positive clients.

\begin{tabular}{|c|c|c|}
\hline & Male & Female \\
\hline Married & 436 & 182 \\
\hline Unmarried & 91 & 34 \\
\hline $\begin{array}{c}\text { Divorced, widow, } \\
\text { widower }\end{array}$ & 3 & 18 \\
\hline \multicolumn{3}{|c|}{ Table 1 } \\
\hline
\end{tabular}

$23 \%$ of the sero-positive clients were housewives. The other occupations were as shown in Table 2.

\begin{tabular}{|c|c|c|}
\hline Occupation & Total Number & $\begin{array}{c}\text { Percentage } \\
\text { Prevalence }\end{array}$ \\
\hline Service & 51 & $7.51 \%$ \\
\hline Housewife & 178 & $22.99 \%$ \\
\hline Business & 124 & $17.02 \%$ \\
\hline Driver & 153 & $19.76 \%$ \\
\hline Private Job & 49 & $7.33 \%$ \\
\hline Unemployed & 10 & $1.29 \%$ \\
\hline Labour & 46 & $6.94 \%$ \\
\hline Defence & 13 & $1.67 \%$ \\
\hline Students & 45 & $5.81 \%$ \\
\hline Retired Person & 75 & $9.68 \%$ \\
\hline & Table 2 \\
\hline
\end{tabular}

Most of the sero-positive clients were educated upto primary level followed by illiterate persons. The figures are shown in Table 3.

\begin{tabular}{|c|c|c|}
\hline Education & Total Number & Percentage \\
\hline Illiterate & 144 & $18.6 \%$ \\
\hline Primary & 541 & $69.89 \%$ \\
\hline Secondary & 49 & $6.33 \%$ \\
\hline Graduate and Above & 40 & $5.18 \%$ \\
\hline \multicolumn{2}{|c}{ Table 3 } \\
\hline
\end{tabular}

Based on the sexual orientation, $77.51 \%$ of the seropositive clients were heterosexuals having multiple partners. As per the source of exposure, sexual route of transmission was the most prevalent mode of transmission followed by parent to child transmission and injection drug users. The data is shown in Table 4. 


\begin{tabular}{|c|c|c|}
\hline Source of Exposure & Total Number & Percentage \\
\hline Sexual & 685 & $89.83 \%$ \\
\hline Parent to Child & 42 & $5.42 \%$ \\
\hline Blood Transfusion & 8 & $1.03 \%$ \\
\hline Injection Drug Users & 27 & $3.48 \%$ \\
\hline MSM & 1 & $0.12 \%$ \\
\hline Infected Syringe & 1 & $0.12 \%$ \\
\hline \multicolumn{3}{|c|}{ Table 4 } \\
\hline
\end{tabular}

\section{DISCUSSION}

The study was conducted for a time period of three years between January 2012 to December 2014 among clients of ICTC of Silchar Medical College and Hospital coming voluntarily or being referred from various departments of the hospital. The prevalence of HIV in this study was found to be 4.12\%. Highest sero-positivity was seen in 2013 (4.61\%). This is very high as compared to sero-prevalence of general population $(0.34 \%)$. Although, Assam as such is not a high prevalent state and in Assam HIV prevalence in general population is $0.09 \%$. The high prevalence of HIV in ICTC of this region is attributable to the fact that it is the only tertiary care referral hospital in south eastern region of Assam catering to not only the population in this region, but also by virtue of its geographical boundaries with Manipur, Mizoram and North Tripura, hence may indirectly reflect high prevalence in neighbouring regions. In a similar study in Assam by NK Hazarika et al, ${ }^{9}$ the prevalence was found to be $4.68 \%$ which is almost similar to our study.

In our study, the positivity rate was lower in females as compared to males. It was consistent with study by BL Sherwal et al $^{10}$ and Madkar et al, ${ }^{11}$ but discordant with study by Vyas et al.12 Their 6 years study showed positivity rate higher in females than males.

It is observed that in our study, higher number of seropositivity was seen in $30-45$ years' age group (51.8\%). It is concordant with study by NK Hazarika et al, ${ }^{9}$ where the rate is $88.27 \%$ in 15 - 49 years' age group, BL Sherwal et al $^{9}$ where the positivity rate in $15-49$ years' age group is $69.2 \%$. According to Vyas et $\mathrm{al}^{12}$ the positivity rate is ranging from $85.99 \%$ to $90.55 \%$ in the age group of 15 - 49 years and according to Madkar et al ${ }^{11}$ the prevalence of HIV infection was highest in the age group of 30 - 39 years followed by 20 29 years. As per national figure, it was also observed that about $89 \%$ of cases occurred among sexually active person aged $20-49$ years.

Majority of the HIV sero-positives belonged to the married group irrespective of the sexes. The married seropositive males pose a threat to their uninfected spouses and as they enter into their reproductive lives and ultimately risk parent to child transmission. Perinatal transmission in this study was found to be $5.42 \%$. According to Vyas et al,12 the same was found to be ranging from $5.6 \%$ to $12 \%$, but according to Joardar et al,13 the rate was found to be $2.63 \%$. Similarly, the study by NK Hazarika et al, ${ }^{9}$ the range of perinatal transmission was between $0.3 \%$ in the year 2008 2009 to $1.1 \%$ in the year $2014-15$.

Unprotected heterosexual contact has come out to be the most common mode of transmission of HIV in the present study accounting to $89.83 \%$ of the cases. It is in concordance to study with Vyas et al,12 where it was found to be $81.6 \%$. Similar findings were found in study by NK Hazarika et al, ${ }^{9}$ where the heterosexual route of transmission was $86.81 \%$.
In India contaminated blood and blood products account for about $2 \%$ of HIV infection, whereas here in our study contaminated blood products account for $1.03 \%$ cases. This signifies that there is adequate screening of the blood before transfusion in our setup.

Injection drug use plays a critical role in HIV epidemic in various regions, particularly in Asia and Southern Europe. In India the badly affected areas are North-East India, especially Manipur. In our study, $3.48 \%$ of the sero-positive client were injection drug abusers. But in a similar study conducted in Assam by NK Hazarika et al, ${ }^{9}$ the prevalence of injection drug abusers was found to be $2.39 \%$.

\section{CONCLUSION}

ICTCs are important for prevention, detection and care of HIV infection. The ICTC of Silchar Medical College and Hospital caters to a huge population catering to not only population of this region, but also surrounding region of Manipur, Mizoram and North Tripura. The study reports for the first time the sero-prevalence of HIV in South eastern region of Assam. The prevalence was found to be $4.12 \%$. There is male preponderance over female from sexually active age group of 30 - 45 years. Hence, we should focus on this age group, especially male group for the prevalence of high rate of HIV transmission. This would help in the development of appropriate policies and strategies to reduce the spread of HIV infection in India. Education profile of sero-positive attendees reveals that primary education group constitute $69.89 \%$ of the clientele. This shows that lower literacy rate is one of the most important factors in the spread of AIDS.

As depicted in our study staying away from family, drivers and businessmen may indulge in some risk behaviours that favours HIV transmission. Commercial sex and substance abuse are family trenched in the social-cultural milieu of the trucking industry in India. This should form more the targeted intervention group. All these findings suggest the need for scaling up of focussed prevention efforts among these groups.

\section{ACKNOWLEDGEMENT}

The authors would like to thank National AIDS Control Organisation (NACO) and Assam State AIDS Control Society (ASACS) for allowing to conduct the study and using the data.

\section{Limitations of the Study}

It could be possible that the data reported here could be biased due to recall error or by social stigma faced by patients in the community.

\section{REFERENCES}

[1] Park K. Park's textbook of preventive and social medicine. $18^{\text {th }}$ edn. Japalpur: M/s. Banarasidas Bhanot Publishers 2005.

[2] UNAIDS. Report on the global AIDS Epidemic. 2012.

[3] UNAIDS. World AIDS Day Report: Results. 2012.

[4] UNAIDS. AIDS at 30: Nation at the cross roads. 2011.

[5] NACO Annual Report 2011-12.

[6] Chandrasekharan P. Dallabetta G, Loo V, et al. Containing HIV/AIDS in India: the unfinished agenda. Lancet Infect Dis 2006;6(8):508-21. 
[7] Dandona L, Lakshmi V, Sudha T, et al. A population based study of Human Immunodeficiency Virus in South India reveals major differences from sentinel surveillance-based estimates. BMC Med 2006;4:31.

[8] Rao JVRP, Ganguly NK, Mehendale SM, et al. India's response to the HIV epidemic. Lancet 2004;364(9442):1296-7.

[9] Hazarika NK, Alam ST, Sarmah A, et al. A retrospective study on the prevalence of HIV among patients attending a tertiary care hospital of North East India. World Journal of AIDS 2016;6(2):65-73. http://dx.doi.org/10.4236/wja.2016.62010.

[10] Sherwal BL, Gupta P, Nayak R, et al. Prevalence of HIV in a tertiary care centre in Delhi: a five-year ICTC based study. World Journal of AIDS 2015;5:1-9. http://dx.doi.org/10.4236/wja.2015.51001
[11] Madkar SS, Nilekar SL, Vankudre AJ. Prevalence of HIV infection among persons attending Integrated Counseling and Testing Centre, Ambajogai. National Journal of Community Medicine 2011;2(2):213-5.

[12] Vyas N, Hooja S, Sinha P, et al. Prevalence of HIV/AIDS and prediction of future trends in north-west region of India: a six year ICTC based study. Indian Journal of Community Medicine 2009;34(3):212-7. http://dx.doi.org/10.4103/0970-0218.55286

[13] Joardar GK, Sarkar A, Chatterjee C, et al. Profiles of attendees in the voluntary counseling and testing center of north Bengal medical college in Darjeeling district of West Bengal. Indian Journal of Community Medicine 2006;31:237-40. 